\title{
Prostitution and risk of HIV: male partners of female prostitutes
}

\author{
Sophie Day, Helen Ward, Louise Perrotta
}

Abstract

Objective-To describe risk behaviours for infection with HIV in male sexual partners of female prostitutes.

Design-A cross sectional study.

Setting-Genitourinary medicine clinic, St Mary's Hospital, London.

Subjects-112 self identified male sexual partners of female prostitutes: 101 who reported commerical sexual relationships only, five who reported noncommercial relationships only, and six who reported both commercial and non-commercial relationships.

Main outcome measures-Reported risk behaviours for infection with HIV.

Results-Of the 40 men who had had previous HIV tests or were tested during the study, two (5\%) were infected with HIV. Of the men who would answer the questions, 34/94 reported having sex with other men, 2/105 reported using injected drugs, 8/105 had a history of blood transfusion, 14/108 reported a past history of gonorrhoea, 44/102 reported paying for sex abroad, and $8 / 92$ said that they had also been paid for sex. Of the 55 men who reported paying for vaginal intercourse in the past year, $45(82 \%)$ said that they had always used a condom. In contrast, of the 11 non-paying partners of prostitutes, only two $(18 \%)$ reported ever using a condom with their partners.

Conclusions-Men who have sex with female prostitutes cannot be assumed to be at risk of infection with HIV only by this route: homosexual contact may place them at greater risk. Despite the heterogeneity among male sexual partners of prostitutes, patterns of use of condoms were uniform when they were considered as a reflection of the type of relationship a man had with a female prostitute rather than a consequence of an individual's level of risk.

\section{Introduction}

Research on the risk of infection with HIV and commercial sex has been criticised for focusing on those who sell rather than on those who purchase sexual services. ${ }^{1}$ Moreover, it is generally assumed that the risk of infection among partners of prostitutes derives from their contact with prostitutes. ${ }^{2}$ In the West, studies of male clients of prostitutes have shown a low prevalence of infection among those with no other identified risk behaviour. ${ }^{34}$ In London, of 117 men who cited contact with prostitutes as a risk factor when requesting HIV screening during 1986-9, three were positive for antibodies to HIV $-1 .^{5}$ Two of the three men also reported having sex with male partners while the third reported contact with female prostitutes in Thailand as his only risk.

The frequency of contact with prostitutes in the general population is not known, although various estimates have been made. ${ }^{6-8}$ In a pilot study in 1990 we interviewed a random sample of 147 men attending the genitourinary medicine clinic at St Mary's Hospital: 31 (21\% (95\% confidence interval $14 \cdot 4 \%$ to $27 \cdot 6 \%$ )) reported purchasing sexual services, including nine in the past year. This is likely to overestimate the population frequency given the characteristics of men attending the genitourinary medicine clinic. Since there are many more customers of prostitutes than there are prostitutes, however, the practices of clients may be important in the transmission of HIV.

The present study was designed to complement our cross sectional study of prostitutes ${ }^{9}$ by interviewing both paying (clients) and non-paying (boyfriends or husbands) partners of female prostitutes. The objective was to describe known risk factors for infection with HIV and risk behaviours associated with different sexual relationships.

\section{Subjects and methods}

Current partners of prostitutes are not easily identified and no strict sampling method is practical. We therefore introduced a range of recruitment methods, including publicity in and referrals from genitourinary medicine clinics and voluntary agencies in London and advertisements in local newspapers and a national contact magazine. Telephone interviews were offered to those who were unwilling or unable to attend an interview in person.

The structured interviews included questions on subjects' medical histories, risk factors for infection with HIV, sexual behaviour, and basic sociodemographic characteristics. The detailed questions on commercial and non-commercial sexual relationships included appropriate interviewer probes on circumstance and context according to standard anthropological methods.

Quantifiable data were stored on a standard data entry system. Detailed notes were taken from interviews; personal interviews were taped and transcribed, with consent. Qualitative data were stored on a word processing package, and sorted by content and the interviewer's annotations for further analysis.

\section{Results}

Altogether 112 men participated in the study during 1990-1: 107 were clients of female prostitutes and 11 were non-paying partners (including six who had also been clients). Most of the men (75) had responded to advertisements in a national contact magazine; 24 were recruited through the genitourinary medicine clinic, and 13 through other methods (referred from other clinics or through prostitutes). Forty seven interviews were conducted face to face and 65 by telephone. There were a further six hoax telephone calls, which were terminated by the interviewer or the caller. Some men did not answer all the questions, as shown by the different denominators in subsequent results.

A total of 24 men reported having had HIV tests, 16 in the past year and eight in the past 2-4 years. A further 16 men were tested during the study. The results were pooled to give an overall prevalence of infection with HIV of $5 \%(2 / 40)$. One of the infected men reported heterosexual contact as his only risk while the other reported homosexual contact as well. Neither reported past use of injected drugs. Both men were clients of prostitutes.

Of the men who replied, $2 \%(2 / 105)$ reported past use of injected drugs; $8 \%(8 / 105)$ had a history of blood transfusion or receipt of other blood products; $13 \%$
Correspondence to: Dr Day.

BMf 1993;307:359-61 
$(14 / 108)$ reported a past history of gonorrhoea; and $36 \%$ (34/94) reported ever having had sex with another man. Of the 15 who reported having sex with other men in the past year, six reported taking part in anal intercourse. During their most recent contacts all six men had used condoms, and one reported a condom failing.

The 107 clients reported a wide range of numbers of contacts with prostitutes: estimates of $0-200$ (median 4) in the past year and 1-1200 (median 10) in total. The clients met prostitutes in a variety of ways: their most recent contact was made by advertisements (44), on the streets (18), at saunas and clubs (18), through escort agencies and private referrals (six) and in other ways (21). Of these most recent contacts, 36 had involved a "regular" prostitute already known to the client. Of the 102 men who answered the question, 44 reported paying for sex outside the United Kingdom since 1980. Sexual services had been bought all over the world but predominantly in Europe. Eight of the 92 men who replied said that they had also been paid for sex.

Of the 84 men who reported paying for sex in the past year, 55 reported having vaginal sex and 45 of these reported always using a condom. Some use of condoms during penetrative or non-penetrative sex with prostitutes in the past year was reported by 79 clients, of whom 23 said that one or more condoms had failed. Condoms were used in commercial sex for reasons of safety, primarily to prevent passage of sexually transmitted infections and HIV. Clients reported that prostitutes generally insisted on and provided condoms.

Accounts of commercial sexual activity illustrated diverse interpretations, motivations, and practices. Prostitutes' services were bought habitually by some and occasionally by others. They provided an acceptable "extramarital" activity to those in stable relationships, given the relative anonymity and lack of intimacy. For many, they provided an opportunity to participate in specialised activities that were not considered normal in other relationships. For a minority, they provided social rather than sexual services. Some contacts were associated with work: prostitutes' services were offered during business negotiations or, more commonly, were actively sought by clients who were away from home. Clients made use of common but varied idioms for talking about commercial sex. Many spoke of a need for sex, an appetite which had to be satisfied. Some referred to commercial sex as simply one of many forms of consumerism. Few, however, had discussed these activities before.

Ninety clients of prostitutes also reported having had non-commercial sexual partners in the past year. The table shows the reported use of condoms for vaginal intercourse with commercial and non-commercial partners: most of the men always used a condom with a prostitute; most used a condom at least sometimes with casual, non-commercial partners; but few used a condom with regular non-commercial partners (wife or steady girlfriend). Similar distinctions between paid and unpaid sex were made by the 11 men who reported non-commercial relationships with prostitutes: the six men who had also paid for sexual

Number (percentage) of clients of prostitutes who had also had non-commercial sexual partners by reported use of condoms for vaginal intercourse in past year

\begin{tabular}{lccc}
\hline & & \multicolumn{2}{c}{ With non-commercial partner } \\
\cline { 3 - 4 } Use of condoms & With prostitute & Casual $(\mathrm{n}=51)$ & Regular $(\mathrm{n}=75)^{\star}$ \\
\hline Always & $45(82)$ & $22(43)$ & $21(28)$ \\
Sometimes & $9(16)$ & $11(22)$ & $11(15)$ \\
Never & $1(2)$ & $18(35)$ & $43(57)$ \\
\hline *Wife or steady girlfriend, for example. & &
\end{tabular}

${ }^{\star}$ Wife or steady girlfriend, for example.

\section{Public health implications}

- Men who have sex with prostitutes have been assumed to be at risk of HIV infection mainly from this route, but little is known about their other risk behaviours

- In this study of men who had sex with female prostitutes more than one third reported having had sex with other men

- While commercial partners of prostitutes (clients) almost always used condoms for intercourse condom failures were commonly reported, and non-commercial partners of prostitutes (boyfriends or husbands) very rarely used condoms

- In Britain female prostitutes may be at risk from their partners as much as these men are at risk from prostitutes

intercourse in the past year reported always using a condom during such liaisons while only two men reported ever using a condom with their regular partners.

Not using a condom with their regular prostitute partner did not signify high risk behaviour to these men but rather intimacy, trust, and fidelity. This was seen particularly clearly in two cases involving men who initially knew their girlfriends as paid sex partners. Both men said that they stopped using condoms with their partners when a non-commercial relationship developed.

\section{Discussion}

Subjects were not randomly selected in this study, and results must be interpreted with care. Many participants were recruited through advertising and were likely to have been current, habitual clients of prostitutes. The $5 \%$ prevalence of infection with HIV cannot be generalised because of likely bias in those tested and the time since some of the tests were carried out. In the absence of a more representative sample, these results demonstrate considerable heterogeneity among prostitutes' sexual partners and suggest some conclusions.

As with prostitutes, ${ }^{10}$ the use of condoms by these men was determined primarily by the nature of a relationship: they were likely to use a condom when paying for sex, they might use a condom with a casual partner, but they were unlikely to use a condom with their wife or steady girlfriend even if she was a prostitute. In commercial partnerships the costs and benefits of all aspects of the relationship were considered explicitly, including the use of condoms and the risk of sexually transmitted infections. In noncommercial partnerships, however, these considerations were largely absent, and longer term relationships were ideally governed by sentiment and were regarded as intimate and therefore somehow safe. Use of condoms was not associated with individuals' levels of risk of infection with HIV, and interventions to reduce the risk of transmission of HIV must focus on social relationships as well as individual behaviours.

Men who have sex with prostitutes have been assumed to be at risk of infection with HIV solely from this route. This study, however, found a high prevalence of other known risk factors for infection among the subjects. Thus $35.5 \%$ of the men reported past sexual contacts with other men. Homosexual behaviour presents an additional risk of infection with HIV in this group that may be similar to that presented by use of injected drugs among prostitutes. As condom 
failures during commercial sex were also apparently common, it is possible that female prostitutes are as much at risk of infection from their clients as clients are at risk from prostitutes.

Female prostitutes and their male sexual partners together appear to link otherwise separate parts of large populations through a range of relationships. Further research on these sexual networks and the interconnections between different risk behaviours is needed for the assessment of potential transmission of HIV.

We thank participants for their patience and help with this research; Forum magazine for publicity; and Jonathan Weber and David Miller for helpful technical and editorial comments on a draft of this paper. This study was supported by North West Thames Regional Health Authority and the Jefferiss Research Trust.

1 Alexander P. Prostitutes are being scapegoated for heterosexual AIDS. In Delacoste F, Alexander P, eds. Sex work: writings by women in the sex industry. London: Virago Press, 1990:15-23.

\section{Risk behaviours among male clients of female prostitutes}

\author{
Marina A Barnard, Neil P McKeganey, \\ Alastair H Leyland
}

Public Health Research Unit, University of Glasgow, Glasgow G12 8RZ

Marina A Barnard, research fellow

Neil P McKeganey, senior research fellow

Alastair H Leyland,

statistician

Correspondence to:

Dr Barnard.

$B M 71993 ; 307: 361-2$ largely covert.
In contrast to research on prostitutes' risk behaviours related to infection with HIV, little work has been done on the sexual behaviours of prostitutes' clients. Such research is bedevilled with problems of recruitment and obtaining a representative sample, making use of conventional survey methods difficult. In this study we recruited 143 clients of prostitutes. Although the results cannot be seen as representative, they shed some light on aspects of sexual behaviour that are

\section{Subjects, methods, and results}

Clients were recruited in three settings and asked to complete a short structured questionnaire: 68 were recruited in two genitourinary clinics in Glasgow; 66 were interviewed by telephone after answering an advertisement we had placed in a national tabloid; and nine were cold contacted in Glasgow's red light area (the small number contacted in this way reflecting the difficulties associated with this form of recruitment). The results for the men recruited by the last two methods were combined to give a non-clinic group for statistical analysis.

The table shows some of the background characteristics of the clients. The men reported having paid for sexual services a median of seven times (range 1-2000) since 1980. Higher numbers of contacts were reported by the non-clinic group: $28(37 \%)$ of these men reported having had 21-50 contacts, significantly

Characteristics of male clients of prostitutes in Glasgow who were recruited from two genitourinary clinics (clinic group) or by advertisements or by direct contact in red light district (non-clinic group). Values are numbers (percentages) unless otherwise stated

\begin{tabular}{|c|c|c|c|}
\hline & $\begin{array}{l}\text { Clinic } \\
\text { group } \\
(n=68)\end{array}$ & $\begin{array}{l}\text { Non-clinic } \\
\text { group } \\
(n=75)\end{array}$ & $\begin{array}{c}\text { Total } \\
(n=143)\end{array}$ \\
\hline Mean (range) age (years) & $36 \cdot 8(21-60)$ & $35 \cdot 2(23-63)$ & $36 \cdot 0(21-63)$ \\
\hline Unemployed & $10(15)$ & $6(8)$ & $16(11)$ \\
\hline Married or cohabiting & $23(34)$ & $49(65)$ & $72(50)$ \\
\hline \multicolumn{4}{|l|}{ History of sexually transmitted } \\
\hline infection & $31(46)$ & $4(5)$ & $35(24)$ \\
\hline Tested for HIV & $31(46)$ & $12(16)$ & $43(30)$ \\
\hline
\end{tabular}

2 Plummer FA, Nagelkerke NJD, Moses S, Ndinya-Achola JO, Bwayo J, Ngugi E. The importance of core groups in the epidemiology and control of HIV infection. AIDS 1991;5(suppl 1):S169-76.

3 Wallace J, Mann J, Beatrice S. HIV exposure among clients of prostitutes. In: Organising Committee, ed. Proceedings of IV international conference on AIDS, fune 12-16, 1988, Stockholm. Stockholm: Organising Committee, AIDS, fune 12-16, 1988,
1988:273. (Abstract 4055.)

4 Chiasson NA, Stoneburner R, Lifson A, Hildebrandt D, Jaffe H. No association between HIV-1 seropositivity and prostitute contact in New York City. In: Organising Committee, ed. Proceedings of IV international conference on AIDS, fune 12-16, 1988, Stockholm. Stockholm: Organising Committee, 1988:273. (Abstract 4053.)

5 Ward H, Day S. Prostitution. In: Harris JRW, Forster S, eds. Recent advances in STD and AIDS - 4. Edinburgh: Churchill Livingstone, 1990:183-99.

6 McLeod E. Women working: prostitution now. London: Croom Helm, 1982.

7 Kinnell H. Prostitutes, their clients and risks of HIV infection in Birmingham. Occasional paper. Birmingham: Central Birmingham Health Authority, 1989.

8 Melbye M, Biggar RJ. Interactions between persons at risk for AIDS and the general population in Denmark. Am $\mathcal{f}$ Epidemiol 1992;135:593-602.

9 Ward H, Day S, Mezzone J, Dunlop L, Donegan C, Farrar S, et al. Prostitution and risk of HIV: female prostitutes in London. BMf 1993;307: Prostit.

10 Day S. Anthropological perspectives on sexually transmitted diseases. In: Job-Spira N, Spencer B, Moalti JP, Bouvet E, eds. Sante publique et maladies a transmission sexuelle. Paris: John Libbey Eurotext, 1990:88-97.

(Accepted 26 May 1993)

more than the clinic group, $28(41 \%)$ of whom reported having had 1-10 contacts.

The median time that had elapsed since the men's last contact with a prostitute was 60 days. Most of the men (103) reported having paid for vaginal intercourse during this contact; 89 paid for masturbation or other non-penetrative sex; 87 paid for oral sex; and 11 paid for anal intercourse. Clearly, some men engaged in more than one sexual activity. Condoms were not used by 17 men when they had last paid for vaginal intercourse and by 31 men when they last had oral sex, but all anal intercourse was reportedly protected. Condom failure was reported by $14 \%$ $(19 / 133)$ of those who had used a condom when they had last purchased sexual services. Having unprotected vaginal intercourse was most likely to be reported by men who contacted prostitutes working on the streets: $32 \%(10 / 31)$ of these men had not used a condom during their last contact. Most clients reported having had no previous sexual contact with the prostitutes from whom they purchased unprotected sex.

Most men (121) reported having private, noncommercial sexual contacts: 79 reported having one sexual partner, and 42 reported having two or more concurrent sexual partners (range 2-20), two of whom reported sexual contacts with other men. Most men (117) reported having had vaginal intercourse while 85 had had oral sex, 82 had had other non-penetrative sex, and 16 had had anal intercourse. A minority of these men reported always using condoms with their partners: $24 \%(27 / 114)$ of those having vaginal intercourse, $5 \%(4 / 80)$ of those having oral sex, and $33 \%$ $(5 / 15)$ of those having anal intercourse. No relation was found between condom use and number of private partners. Ten men reported at least one condom failing with a partner in the past year.

\section{Comment}

Condoms were used for most of the commercial sexual contacts reported in this study. In view of the low levels of infection with HIV among female prostitutes $^{1}$ it is probably unwise to overstate the case for heterosexual transmission of HIV through commercial sexual contacts. ${ }^{2}$ Some unprotected sex, however, was reported with prostitutes, mainly women with whom the men had not had previous sexual contact. This contrasts with two studies which found that men were least likely to use condoms with prostitutes of whom they were regular clients. ${ }^{34}$ In addition, condoms were not used with most private sexual partners. These factors suggest that more 